\title{
A New Iterative Method for Solving a System of Generalized Mixed Equilibrium Problems for a Countable Family of Generalized Quasi- $\phi$-Asymptotically Nonexpansive Mappings
}

\author{
Wei-Qi Deng \\ College of Statistics and Mathematics, Yunnan University of Finance and Economics, Kunming, Yunnan 650221, China \\ Correspondence should be addressed to Wei-Qi Deng; dwq1273@126.com
}

Received 3 October 2012; Accepted 4 January 2013

Academic Editor: Satit Saejung

Copyright (C) 2013 Wei-Qi Deng. This is an open access article distributed under the Creative Commons Attribution License, which permits unrestricted use, distribution, and reproduction in any medium, provided the original work is properly cited.

By using a specific way of choosing the indexes, we introduce an up-to-date iterative algorithm for approximating common fixed points of a countable family of generalized quasi- $\phi$-asymptotically nonexpansive mappings and obtain a strong convergence theorem under some suitable conditions. As application, an iterative solution to a system of generalized mixed equilibrium problems is studied. The results extend those of other authors, in which the involved mappings consist of just finite families.

\section{Introduction}

Throughout this paper, we assume that $E$ is a real Banach space with its dual $E^{*}, C$ is a nonempty closed convex subset of $E$, and $J: E \rightarrow 2^{E^{*}}$ is the normalized duality mapping defined by

$$
J x=\left\{f \in E^{*}:\langle x, f\rangle=\|x\|^{2}=\|f\|^{2}\right\}, \quad \forall x \in E .
$$

In the sequel, we use $F(T)$ to denote the set of fixed points of a mapping $T$.

Definition 1. (1) [1] A mapping T:C $\rightarrow C$ is said to be generalized quasi- $\phi$-asymptotically nonexpansive in the light of [1], if $F(T) \neq \emptyset$, and there exist nonnegative real sequences $\left\{v_{n}\right\}$ and $\left\{\mu_{n}\right\}$ with $v_{n}, \mu_{n} \rightarrow 0($ as $n \rightarrow \infty)$ such that

$$
\phi\left(p, T^{n} x\right) \leq\left(1+v_{n}\right) \phi(p, x)+\mu_{n}, \quad \forall n \geq 1, x \in C, p \in F(T),
$$

where $\phi: E \times E \rightarrow \mathbb{R}$ denotes the Lyapunov functional defined by

$$
\phi(x, y)=\|x\|^{2}-2\langle x, J y\rangle+\|y\|^{2}, \quad \forall x, y \in E .
$$

It is obvious from the definition of $\phi$ that

$$
(\|x\|-\|y\|)^{2} \leq \phi(x, y) \leq(\|x\|+\|y\|)^{2} .
$$

(2) A mapping $T: C \rightarrow C$ is said to be uniformly $L^{-}$ Lipschitz continuous, if there exists a constant $L>0$ such that

$$
\left\|T^{n} x-T^{n} y\right\| \leq L\|x-y\|, \quad \forall n \geq 1, x, y \in C .
$$

Example 2. Let $C$ be a unit ball in a real Hilbert space $l^{2}$, and let $T: C \rightarrow C$ be a mapping defined by

$$
T\left(x_{1}, x_{2}, \ldots\right)=\left(0, x_{1}^{2}, a_{2} x_{2}, a_{3} x_{3}, \ldots\right),
$$

where $\left\{a_{i}\right\}$ is a sequence in $(0,1)$ satisfying $\prod_{i=2}^{\infty} a_{i}=1 / 2$. It is shown by Goebel and Kirk [2] that

$$
\phi\left(p, T^{n} y\right) \leq\left(1+v_{n}\right) \phi(p, y)+\mu_{n}, \quad \forall n \geq 1, y \in C, p \in F(T),
$$

where $\phi(x, y)=\|x-y\|^{2}, v_{n}=\left(2 \prod_{i=2}^{n} a_{i}\right)^{2}-1$, for all $n \geq$ 1 , and $\left\{\mu_{n}\right\}$ is a nonnegative real sequence with $\mu_{n} \rightarrow 0$ as $n \rightarrow \infty$. This shows that the mapping $T$ defined earlier is a generalized quasi- $\phi$-asymptotically nonexpansive mapping. 
Let $\theta: C \times C \rightarrow \mathbb{R}$ be a bifunction, $\psi: C \rightarrow \mathbb{R}$ a real valued function, and $B: C \rightarrow E^{*}$ a nonlinear mapping. The so-called generalized mixed equilibrium problem (GMEP) is to find a $u \in C$ such that

$$
\theta(u, y)+\langle y-u, B u\rangle+\psi(y)-\psi(u) \geq 0, \quad \forall y \in C,
$$

whose set of solutions is denoted by $\Omega(\theta, B, \psi)$.

The equilibrium problem is a unifying model for several problems arising in physics, engineering, science optimization, economics, transportation, network and structural analysis, Nash equilibrium problems in noncooperative games, and others. It has been shown that variational inequalities and mathematical programming problems can be viewed as a special realization of the abstract equilibrium problems. Many authors have proposed some useful methods to solve the (equilibrium problem) EP, (generalized equilibrium problem) GEP, (mixed equilibrium problem) MEP, and GMEP. Concerning the weak and strong convergence of iterative sequences to approximate a common element of the set of solutions for the GMEP, the set of solutions to variational inequality problems and the set of common fixed points for relatively nonexpansive mappings, quasi- $\phi$-nonexpansive mappings, and quasi- $\phi$-asymptotically nonexpansive mappings have been studied by many authors in the setting of Hilbert or Banach spaces (e.g., see [3-16] and the references therein).

Inspired and motivated by the study mentioned earlier, in this paper, by using a specific way of choosing the indexes, we propose an up-to-date iteration scheme for approximating common fixed points of a countable family of generalized quasi- $\phi$-asymptotically nonexpansive mappings and obtain a strong convergence theorem for solving a system of generalized mixed equilibrium problems. The results extend those of the authors, in which the involved mappings consist of just finite families.

\section{Preliminaries}

A Banach space $E$ is strictly convex if the following implication holds for $x, y \in E$ :

$$
\|x\|=\|y\|=1, \quad x \neq y \Longrightarrow\left\|\frac{x+y}{2}\right\|<1 .
$$

It is also said to be uniformly convex if for any $\epsilon>0$, there exists a $\delta>0$ such that

$$
\|x\|=\|y\|=1, \quad\|x-y\| \geq \epsilon \Longrightarrow\left\|\frac{x+y}{2}\right\| \leq 1-\delta .
$$

It is known that if $E$ is uniformly convex Banach space, then $E$ is reflexive and strictly convex. A Banach space $E$ is said to be smooth if

$$
\lim _{t \rightarrow 0} \frac{\|x+t y\|-\|x\|}{t}
$$

exists for each $x, y \in S(E):=\{x \in E:\|x\|=1\}$. In this case, the norm of $E$ is said to be Gâteaux differentiable. The space
$E$ is said to have uniformly Gâteaux differentiable norm if for each $y \in S(E)$, the limit (11) is attained uniformly for $x \in S(E)$. The norm of $E$ is said to be Fréchet differentiable if for each $x \in S(E)$, the limit (11) is attained uniformly for $y \in S(E)$. The norm of $E$ is said to be uniformly Fréchet differentiable (and $E$ is said to be uniformly smooth) if the limit (11) is attained uniformly for $x, y \in S(E)$. Note that $E$ ( $E^{*}$, resp.) is uniformly convex $\Leftrightarrow E^{*}$ (E, resp.) is uniformly smooth.

Following Alber [17], the generalized projection $\Pi_{C}: E \rightarrow$ $C$ is defined by

$$
\Pi_{C}(x)=\arg \inf _{y \in C} \phi(y, x), \quad \forall x \in E .
$$

Lemma 3 (see [17]). Let E be a smooth, strictly convex, and reflexive Banach space, and let $C$ be a nonempty closed convex subset of $E$. Then, the following conclusions hold:

(1) $\phi\left(x, \Pi_{C} y\right)+\phi\left(\Pi_{C} y, y\right) \leq \phi(x, y)$ for all $x \in C$ and $y \in E$;

(2) if $x \in E$ and $z \in C$, then $z=\Pi_{C} x \Leftrightarrow\langle z-y, J x-J z\rangle \geq$ 0 , for all $y \in C$;

(3) for $x, y \in E, \phi(x, y)=0$ if and only if $x=y$.

Remark 4. The following basic properties for a Banach space $E$ can be found in Cioranescu [18].

(i) If $E$ is uniformly smooth, then $J$ is uniformly continuous on each bounded subset of $E$.

(ii) If $E$ is reflexive and strictly convex, then $J^{-1}$ is normweak continuous.

(iii) If $E$ is a smooth, strictly convex, and reflexive Banach space, then the normalized duality mapping $J: E \rightarrow$ $2^{E^{*}}$ is single valued, one-to-one, and onto.

(iv) A Banach space $E$ is uniformly smooth if and only if $E^{*}$ is uniformly convex.

(v) Each uniformly convex Banach space $E$ has the KadecKlee property; that is, for any sequence $\left\{x_{n}\right\} \subset E$, if $x_{n} \rightarrow x \in E$ and $\left\|x_{n}\right\| \rightarrow\|x\|$, then $x_{n} \rightarrow x$, where $x_{n} \rightarrow x$ denotes that $\left\{x_{n}\right\}$ converges weakly to $x$.

Lemma 5 (see [19]). Let $E$ be a real uniformly smooth and strictly convex Banach space with Kadec-Klee property, and let $C$ be a nonempty closed convex subset of E. Let $\left\{x_{n}\right\}$ and $\left\{y_{n}\right\}$ be two sequences in $C$ such that $x_{n} \rightarrow p$ and $\phi\left(x_{n}, y_{n}\right) \rightarrow 0$, where $\phi$ is the function defined by (3); then, $y_{n} \rightarrow p$.

Lemma 6 (see [1]). Let $E$ and $C$ be the same as those in Lemma 5. Let $T: C \rightarrow C$ be a closed and generalized quasi$\phi$-asymptotically nonexpansive mapping with nonnegative real sequences $\left\{v_{n}\right\}$ and $\left\{\mu_{n}\right\}$; then, the fixed point set $F(T)$ of $T$ is a closed and convex subset of $C$.

Lemma 7 (see [20]). Let E be a real uniformly convex Banach space, and let $B_{r}(0)$ be the closed ball of $E$ with center at the origin and radius $r>0$. Then, there exists a continuous strictly increasing convex function $g:[0, \infty) \rightarrow[0, \infty)$ with $g(0)=$ 0 such that

$$
\|\alpha x+\beta y\|^{2} \leq \alpha\|x\|^{2}+\beta\|y\|^{2}-\alpha \beta g(\|x-y\|)
$$

for all $x, y, \in B_{r}(0)$, and $\alpha, \beta \in[0,1]$ with $\alpha+\beta=1$. 


\section{Main Results}

Theorem 8. Let $E$ be a real uniformly smooth and strictly convex Banach space with Kadec-Klee property, C a nonempty closed convex subset of $E$, and $T_{i}: C \rightarrow C, i=1,2$, ... a countable family of closed and generalized quasi- $\phi$ asymptotically nonexpansive mappings with nonnegative real sequences $\left\{v_{n}^{(i)}\right\}$ and $\left\{\mu_{n}^{(i)}\right\}$ satisfying $v_{n}^{(i)} \rightarrow 0$ and $\mu_{n}^{(i)} \rightarrow 0$ (as $n \rightarrow \infty$ and for each $i \geq 1$ ), and each $T_{i}$ is uniformly $L_{i}$-Lipschitz continuous. Let $\left\{\alpha_{n}\right\}$ be a sequence in $[0, \epsilon]$ for some $\epsilon \in(0,1)$, and let $\left\{\beta_{n}\right\}$ be a sequence in $[0,1]$ satisfying $0<\liminf _{n \rightarrow \infty} \beta_{n}\left(1-\beta_{n}\right)$. Let $\left\{x_{n}\right\}$ be the sequence generated by

$$
\begin{aligned}
& x_{1} \in C ; \quad C_{1}=C, \\
& y_{n}=J^{-1}\left[\alpha_{n} J x_{n}+\left(1-\alpha_{n}\right) J z_{n}\right], \\
& z_{n}=J^{-1}\left[\beta_{n} J x_{n}+\left(1-\beta_{n}\right) J T_{i_{n}}^{m_{n}} x_{n}\right], \\
& C_{n+1}=\left\{v \in C_{n}: \phi\left(v, y_{n}\right) \leq \phi\left(v, x_{n}\right)+\xi_{n}\right\}, \\
& x_{n+1}=\prod_{C_{n+1}} x_{1}, \quad \forall n \geq 1,
\end{aligned}
$$

where $\xi_{n}:=v_{m_{n}}^{\left(i_{n}\right)} \sup _{p \in F} \phi\left(p, x_{n}\right)+\mu_{m_{n}}^{\left(i_{n}\right)}, \Pi_{C_{n+1}}$ is the generalized projection of $E$ onto $C_{n+1}$, and $i_{n}$ and $m_{n}$ satisfy the positive integer equation: $n=i+(m-1) m / 2, m \geq i(m \geq i, n=$ $1,2, \ldots)$; that is, for each $n \geq 1$, there exist unique $i_{n}$ and $m_{n}$ such that

$$
\begin{array}{ccc}
i_{1}=1, & i_{2}=1, \quad i_{3}=2, & i_{4}=1, \quad i_{5}=2, \\
i_{6}=3, & i_{7}=1, \quad i_{8}=2, \ldots ; \\
m_{1}=1, \quad m_{2}=2, & m_{3}=2, \quad m_{4}=3, \quad m_{5}=3, \\
m_{6}=3, \quad m_{7}=4, \quad m_{8}=4, \ldots
\end{array}
$$

If $F:=\bigcap_{i=1}^{\infty} F\left(T_{i}\right)$ is nonempty and bounded, then $\left\{x_{n}\right\}$ converges strongly to $\Pi_{F} x_{1}$.

Proof. We divide the proof into several steps.

(I) $F$ and $C_{n}$ (for all $n \geq 1$ ) both are closed and convex subsets in $C$.

In fact, it follows from Lemma 6 that each $F\left(T_{i}\right)$ is a closed and convex subset of $C$, so is $F$. In addition, with $C_{1}(=C)$ being closed and convex, we may assume that $C_{n}$ is closed and convex for some $n \geq 2$. In view of the definition of $\phi$, we have that

$$
C_{n+1}=\{v \in C: \varphi(v) \leq a\} \cap C_{n}
$$

where $\varphi(v)=2\left\langle v, J x_{n}-J y_{n}\right\rangle$, and $a=\left\|x_{n}\right\|^{2}-\left\|y_{n}\right\|^{2}+\xi_{n}$. This shows that $C_{n+1}$ is closed and convex.

(II) $F$ is a subset of $\bigcap_{n=1}^{\infty} C_{n}$.
It is obvious that $F \subset C_{1}$. Suppose that $F \subset C_{n}$ for some $n \geq 2$. Since $E$ is uniformly smooth, $E^{*}$ is uniformly convex. Then, for any $p \in F \subset C_{n}$, we have that

$$
\begin{aligned}
\phi\left(p, y_{n}\right)= & \phi\left(p, J^{-1}\left[\alpha_{n} J x_{n}+\left(1-\alpha_{n}\right) J x_{n}\right]\right) \\
= & \|p\|^{2}-2\left\langle p, \alpha_{n} J x_{n}+\left(1-\alpha_{n}\right) J z_{n}\right\rangle \\
& +\left\|\alpha_{n} J x_{n}+\left(1-\alpha_{n}\right) J z_{n}\right\|^{2} \\
\leq & \|p\|^{2}-2 \alpha_{n}\left\langle p, J x_{n}\right\rangle-2\left(1-\alpha_{n}\right)\left\langle p, J z_{n}\right\rangle \\
& +\alpha_{n}\left\|x_{n}\right\|^{2}+\left(1-\alpha_{n}\right)\left\|z_{n}\right\|^{2} \\
= & \alpha_{n} \phi\left(p, x_{n}\right)+\left(1-\alpha_{n}\right) \phi\left(p, z_{n}\right) .
\end{aligned}
$$

Furthermore, it follows from Lemma 7 that for any $p \in F$, we have that

$$
\begin{aligned}
& \phi\left(p, z_{n}\right)=\phi\left(p, J^{-1}\left[\beta_{n} J x_{n}+\left(1-\beta_{n}\right) J T_{i_{n}}^{m_{n}} x_{n}\right]\right) \\
& =\|p\|^{2}-2\left\langle p, \beta_{n} J x_{n}+\left(1-\beta_{n}\right) J T_{i_{n}}^{m_{n}} x_{n}\right\rangle \\
& +\left\|\beta_{n} J x_{n}+\left(1-\beta_{n}\right) J T_{i_{n}}^{m_{n}} x_{n}\right\|^{2} \\
& \leq\|p\|^{2}-2 \beta_{n}\left\langle p, J x_{n}\right\rangle-2\left(1-\beta_{n}\right) \\
& \times\left\langle p, J T_{i_{n}}^{m_{n}} x_{n}\right\rangle+\beta_{n}\left\|x_{n}\right\|^{2}+\left(1-\beta_{n}\right)\left\|T_{i_{n}}^{m_{n}} x_{n}\right\|^{2} \\
& -\beta_{n}\left(1-\beta_{n}\right) g\left(\left\|J x_{n}-J T_{i_{n}}^{m_{n}} x_{n}\right\|\right) \\
& =\beta_{n} \phi\left(p, x_{n}\right)+\left(1-\beta_{n}\right) \phi\left(p, T_{i_{n}}^{m_{n}} x_{n}\right) \\
& -\beta_{n}\left(1-\beta_{n}\right) g\left(\left\|J x_{n}-J T_{i_{n}}^{m_{n}} x_{n}\right\|\right) \\
& \leq \beta_{n} \phi\left(p, x_{n}\right)+\left(1-\beta_{n}\right) \\
& \times\left[\phi\left(p, x_{n}\right)+v_{m_{n}}^{\left(i_{n}\right)} \sup _{p \in F} \phi\left(p, x_{n}\right)+\mu_{m_{n}}^{\left(i_{n}\right)}\right] \\
& -\beta_{n}\left(1-\beta_{n}\right) g\left(\left\|J x_{n}-J T_{i_{n}}^{m_{n}} x_{n}\right\|\right) \\
& \leq \phi\left(p, x_{n}\right)+v_{m_{n}}^{\left(i_{n}\right)} \sup _{p \in F} \phi\left(p, x_{n}\right)+\mu_{m_{n}}^{\left(i_{n}\right)} \\
& -\beta_{n}\left(1-\beta_{n}\right) g\left(\left\|J x_{n}-J T_{i_{n}}^{m_{n}} x_{n}\right\|\right) \\
& =\phi\left(p, x_{n}\right)+\xi_{n}-\beta_{n}\left(1-\beta_{n}\right) g\left(\left\|J x_{n}-J T_{i_{n}}^{m_{n}} x_{n}\right\|\right) \text {. }
\end{aligned}
$$

Substituting (18) into (17) and simplifying it, we have that

$$
\phi\left(p, y_{n}\right) \leq \phi\left(p, x_{n}\right)+\left(1-\alpha_{n}\right) \xi_{n} \leq \phi\left(p, x_{n}\right)+\xi_{n} .
$$

This implies that $p \in C_{n+1}$, and so $F \subset C_{n+1}$.

(III) $x_{n} \rightarrow x^{*} \in C$ as $n \rightarrow \infty$.

In fact, since $x_{n}=\Pi_{C_{n}} x_{1}$, from Lemma 3 (2), we have that $\left\langle x_{n}-y, J x_{1}-J x_{n}\right\rangle \geq 0$, for all $y \in C_{n}$. Again, since 
$F \subset \bigcap_{n=1}^{\infty} C_{n}$, we have that $\left\langle x_{n}-p, J x_{1}-J x_{n}\right\rangle \geq 0$, for all $p \in F$. It follows from Lemma 3 (1) that for each $p \in F$ and for each $n \geq 1$,

$$
\phi\left(x_{n}, x_{1}\right)=\phi\left(\Pi_{C_{n}} x_{1}, x_{1}\right) \leq \phi\left(p, x_{1}\right)-\phi\left(p, x_{n}\right) \leq \phi\left(p, x_{1}\right),
$$

which implies that $\left\{\phi\left(x_{n}, x_{1}\right)\right\}$ is bounded, so is $\left\{x_{n}\right\}$. Since for all $n \geq 1, x_{n}=\Pi_{C_{n}} x_{1}$ and $x_{n+1}=\Pi_{C_{n+1}} x_{1} \in C_{n+1} \subset C_{n}$, we have $\phi\left(x_{n}, x_{1}\right) \leq \phi\left(x_{n+1}, x_{1}\right)$. This implies that $\left\{\phi\left(x_{n}, x_{1}\right)\right\}$ is nondecreasing; hence, the limit

$$
\lim _{n \rightarrow \infty} \phi\left(x_{n}, x_{1}\right) \text { exists. }
$$

Since $E$ is reflexive, there exists a subsequence $\left\{x_{n_{i}}\right\}$ of $\left\{x_{n}\right\}$ such that $x_{n_{i}} \rightarrow x^{*} \in C$ as $i \rightarrow \infty$. Since $C_{n}$ is closed and convex and $C_{n+1} \subset C_{n}$, this implies that $C_{n}$ is weakly, closed and $x^{*} \in C_{n}$ for each $n \geq 1$. In view of $x_{n_{i}}=\prod_{C_{n_{i}}} x_{1}$, we have that

$$
\phi\left(x_{n_{i}}, x_{1}\right) \leq \phi\left(x^{*}, x_{1}\right), \quad \forall i \geq 1 .
$$

Since the norm $\|\cdot\|$ is weakly lower semicontinuous, we have that

$$
\begin{aligned}
\liminf _{i \rightarrow \infty} \phi\left(x_{n_{i}}, x_{1}\right) & =\liminf _{i \rightarrow \infty}\left(\left\|x_{n_{i}}\right\|^{2}-2\left\langle x_{n_{i}}, J x_{1}\right\rangle+\left\|x_{1}\right\|^{2}\right) \\
& \geq\left\|x^{*}\right\|^{2}-2\left\langle x^{*}, J x_{1}\right\rangle+\left\|x_{1}\right\|^{2} \\
& =\phi\left(x^{*}, x_{1}\right),
\end{aligned}
$$

and so

$$
\phi\left(x^{*}, x_{1}\right) \leq \liminf _{i \rightarrow \infty} \phi\left(x_{n_{i}}, x_{1}\right) \leq \limsup _{i \rightarrow \infty} \phi\left(x_{n_{i}}, x_{1}\right) \leq \phi\left(x^{*}, x_{1}\right) .
$$

This implies that $\lim _{i \rightarrow \infty} \phi\left(x_{n_{i}}, x_{1}\right)=\phi\left(x^{*}, x_{1}\right)$, and so $\left\|x_{n_{i}}\right\| \rightarrow\left\|x^{*}\right\|$ as $i \rightarrow \infty$. Since $x_{n_{i}} \rightarrow x^{*}$, by virtue of KadecKlee property of $E$, we obtain that

$$
\lim _{i \rightarrow \infty} x_{n_{i}}=x^{*}
$$

Since $\left\{\phi\left(x_{n}, x_{1}\right)\right\}$ is convergent, this, together with $\lim _{i \rightarrow \infty} \phi\left(x_{n_{i}}, x_{1}\right)=\phi\left(x^{*}, x_{1}\right)$, shows that $\lim _{n \rightarrow \infty} \phi\left(x_{n}\right.$, $\left.x_{1}\right)=\phi\left(x^{*}, x_{1}\right)$. If there exists some subsequence $\left\{x_{n_{j}}\right\}$ of $\left\{x_{n}\right\}$ such that $x_{n_{j}} \rightarrow y$ as $j \rightarrow \infty$, then, from Lemma 3 (1), we have that

$$
\begin{aligned}
\phi\left(x^{*}, y\right) & =\lim _{i, j \rightarrow \infty} \phi\left(x_{n_{i}}, x_{n_{j}}\right)=\lim _{i, j \rightarrow \infty} \phi\left(x_{n_{i}}, \Pi_{C_{n_{j}}} x_{1}\right) \\
& \leq \lim _{i, j \rightarrow \infty}\left(\phi\left(x_{n_{i}}, x_{1}\right)-\phi\left(\Pi_{C_{n_{j}}} x_{1}, x_{1}\right)\right) \\
& =\lim _{i, j \rightarrow \infty}\left(\phi\left(x_{n_{i}}, x_{1}\right)-\phi\left(x_{n_{j}}, x_{1}\right)\right) \\
& =\phi\left(x^{*}, x_{1}\right)-\phi\left(x^{*}, x_{1}\right)=0 ;
\end{aligned}
$$

that is, $x^{*}=y$, and so

$$
\lim _{n \rightarrow \infty} x_{n}=x^{*}
$$

(IV) $x^{*}$ is some member of $F$.

Set $\mathscr{K}_{i}=\{k \geq 1: k=i+(m-1) m / 2, m \geq i, m \in \mathbb{N}\}$ for each $i \geq 1$. Note that $v_{m_{n}}^{\left(i_{k}\right)}=v_{m_{k}}^{(i)}$ and $\mu_{m_{n}}^{\left(i_{k}\right)}=\mu_{m_{k}}^{(i)}$ whenever $k \in \mathscr{K}_{i}$ for each $i \geq 1$. For example, by the definition of $\mathscr{K}_{1}$, we have that $\mathscr{K}_{1}=\{1,2,4,7,11,16, \ldots\}$, and $i_{1}=i_{2}=i_{4}=$ $i_{7}=i_{11}=i_{16}=\cdots=1$. Then, we have that

$$
\xi_{k}=v_{m_{k}}^{(i)} \sup _{p \in F} \phi\left(p, x_{k}\right)+\mu_{m_{k}}^{(i)}, \quad \forall k \in \mathscr{K}_{i} .
$$

Note that $\left\{m_{k}\right\}_{k \in \mathscr{K}_{i}}=\{i, i+1, i+2, \ldots\}$; that is, $m_{k} \uparrow \infty$ as $\mathscr{K}_{i} \ni k \rightarrow \infty$. It follows from (27) and (28) that

$$
\lim _{\mathscr{K}_{i} \ni k \rightarrow \infty} \xi_{k}=0 \text {. }
$$

Since $x_{n+1} \in C_{n+1}$, it follows from (14), (27), and (29) that

$$
\phi\left(x_{k+1}, y_{k}\right) \leq \phi\left(x_{k+1}, x_{k}\right)+\xi_{k} \longrightarrow 0
$$

as $\mathscr{K}_{i} \ni k \rightarrow \infty$. Since $x_{k} \rightarrow x^{*}$ as $\mathscr{K}_{i} \ni k \rightarrow \infty$, it follows from (30) and Lemma 5 that

$$
\lim _{\mathscr{K}_{i} \ni k \rightarrow \infty} y_{k}=x^{*} .
$$

Note that $T_{i_{k}}^{m_{k}}=T_{i}^{m_{k}}$ whenever $k \in \mathscr{K}_{i}$ for each $i \geq 1$. From (17) and (18), for any $p \in F$, we have that

$$
\begin{aligned}
\phi\left(p, y_{k}\right) \leq & \phi\left(p, x_{k}\right)+\xi_{k}-\left(1-\alpha_{k}\right) \beta_{k}\left(1-\beta_{k}\right) g \\
& \times\left(\left\|J x_{k}-J T_{i}^{m_{k}} x_{k}\right\|\right) ;
\end{aligned}
$$

that is,

$$
\begin{aligned}
& \left(1-\alpha_{k}\right) \beta_{k}\left(1-\beta_{k}\right) g\left(\left\|J x_{k}-J T_{i}^{m_{k}} x_{k}\right\|\right) \\
& \quad \leq \phi\left(p, x_{k}\right)+\xi_{k}-\phi\left(p, y_{k}\right) \longrightarrow 0 \quad\left(\mathscr{K}_{i} \ni k \longrightarrow \infty\right) .
\end{aligned}
$$

This, together with assumption conditions imposed on the sequences $\left\{\alpha_{n}\right\}$ and $\left\{\beta_{n}\right\}$, shows that $\lim _{\mathscr{K}_{i} \ni k \rightarrow \infty} g\left(\| J x_{k}-\right.$ $\left.J T_{i}^{m_{k}} x_{k} \|\right)=0$. In view of property of $g$, we have that

$$
\lim _{\mathscr{K}_{i} \ni k \rightarrow \infty}\left\|J x_{k}-J T_{i}^{m_{k}} x_{k}\right\|=0 .
$$

In addition, $J x_{k} \rightarrow J x^{*}$ implies that $\lim _{\mathscr{K}_{i} \ni k \rightarrow \infty} J T_{i}^{m_{k}} x_{k}=$ $J x^{*}$. From Remark 4 (ii), it yields that, as $\mathscr{K}_{i} \ni k \rightarrow \infty$,

$$
T_{i}^{m_{k}} x_{k} \rightarrow x^{*}, \quad \forall i \geq 1 .
$$

Again, since for each $i \geq 1$, as $\mathscr{K}_{i} \ni k \rightarrow \infty$,

$$
\left\|T_{i}^{m_{k}} x_{k}\right\|-\left\|x^{*}\right\||=|\left\|J T_{i}^{m_{k}} x_{k}\right\|-\left\|J x^{*}\right\| \mid \leq\left\|J T_{i}^{m_{k}} x_{k}-J x^{*}\right\| \longrightarrow 0 .
$$

This, together with (35) and the Kadec-Klee property of E, shows that

$$
\lim _{\mathscr{K}_{i} \ni k \rightarrow \infty} T_{i}^{m_{k}} x_{k}=x^{*}, \quad \forall i \geq 1 .
$$


On the other hand, by the assumptions that for each $i \geq 1, T_{i}$ is uniformly $L_{i}$-Lipschitz continuous, and noting again that $\left\{m_{k}\right\}_{k \in \mathscr{K}_{i}}=\{i, i+1, i+2, \ldots\}$, that is, $m_{k+1}-1=m_{k}$ for all $k \in \mathscr{K}_{i}$, we then have

$$
\begin{aligned}
\left\|T_{i}^{m_{k+1}} x_{k}-T_{i}^{m_{k}} x_{k}\right\| \leq & \left\|T_{i}^{m_{k+1}} x_{k}-T_{i}^{m_{k+1}} x_{k+1}\right\| \\
& +\left\|T_{i}^{m_{k+1}} x_{k+1}-x_{k+1}\right\| \\
& +\left\|x_{k+1}-x_{k}\right\|+\left\|x_{k}-T_{i}^{m_{k}} x_{k}\right\| \\
\leq & \left(L_{i}+1\right)\left\|x_{k+1}-x_{k}\right\|+\left\|T_{i}^{m_{k+1}} x_{k+1}-x_{k+1}\right\| \\
& +\left\|x_{k}-T_{i}^{m_{k}} x_{k}\right\| .
\end{aligned}
$$

From (37) and $x_{k} \rightarrow x^{*}$, we have that $\lim _{\mathscr{K}_{i} \ni k \rightarrow \infty} \| T_{i}^{m_{k+1}} x_{k}-$ $T_{i}^{m_{k}} x_{k} \|=0$, and $\lim _{\mathscr{K}_{i} \ni k \rightarrow \infty} T_{i}^{m_{k+1}} x_{k}=x^{*}$; that is, $\lim _{\mathscr{K}_{i} \ni k \rightarrow \infty} T_{i}\left(T_{i}^{m_{k+1}-1} x_{k}\right)=x^{*}$. It then follows that, for each $i \geq 1$,

$$
\lim _{\mathscr{K}_{i} \ni k \rightarrow \infty} T_{i}\left(T_{i}^{m_{k}} x_{k}\right)=x^{*}
$$

In view of the closeness of $T_{i}$, it follows from (37) that $T_{i} x^{*}=$ $x^{*}$, namely, for each $i \geq 1, x^{*} \in F\left(T_{i}\right)$, and, hence, $x^{*} \in F$.

(V) $x^{*}=\Pi_{F} x_{1}$, and so $x_{n} \rightarrow \Pi_{F} x_{1}$ as $n \rightarrow \infty$.

Put $u=\Pi_{F} x_{1}$. Since $u \in F \subset C_{n}$ and $x_{n}=\Pi_{C_{n}} x_{1}$, we have that $\phi\left(x_{n}, x_{1}\right) \leq \phi\left(u, x_{1}\right)$, for all $n \geq 1$. Then,

$$
\phi\left(x^{*}, x_{1}\right)=\lim _{n \rightarrow \infty} \phi\left(x_{n}, x_{1}\right) \leq \phi\left(u, x_{1}\right),
$$

which implies that $x^{*}=u$ since $u=\prod_{F} x_{1}$, and, hence, $x_{n} \rightarrow$ $x^{*}=\Pi_{F} x_{1}$.

This completes the proof.

\section{Applications}

Let $E$ be a smooth, strictly convex, and reflexive Banach space, and let $C$ be a nonempty closed convex subset of $E$. Let $\left\{B_{i}\right\}_{i=1}^{\infty}: C \rightarrow E^{*}$ be a sequence of $\beta_{i}$-inverse strongly monotone mappings, $\{\psi\}_{i=1}^{\infty}: C \rightarrow \mathbb{R}$ a sequence of lower semicontinuous and convex functions, and $\left\{\theta_{i}\right\}_{i=1}^{\infty}: C \times$ $C \rightarrow \mathbb{R}$ a sequence of bifunctions satisfying the following conditions:

$\left(\mathrm{A}_{1}\right) \theta(x, x)=0$

$\left(\mathrm{A}_{2}\right) \theta$ is monotone; that is, $\theta(x, y)+\theta(y, x) \leq 0$;

$\left(\mathrm{A}_{3}\right) \lim \sup _{t \downarrow 0} \theta(x+t(z-x), y) \leq \theta(x, y)$;

$\left(\mathrm{A}_{4}\right)$ the mapping $y \mapsto \theta(x, y)$ is convex and lower semicontinuous.

A system of generalized mixed equilibrium problems (GMEPs), for $\left\{\theta_{i}\right\}_{i=1}^{\infty},\left\{B_{i}\right\}_{i=1}^{\infty}$, and $\left\{\psi_{i}\right\}_{i=1}^{\infty}$ is to find an $x^{*} \in C$ such that

$$
\begin{array}{r}
\theta_{i}\left(x^{*}, y\right)+\left\langle y-x^{*}, B_{i} x^{*}\right\rangle+\psi_{i}(y)-\psi_{i}\left(x^{*}\right) \geq 0, \\
\forall y \in C, i \geq 1,
\end{array}
$$

whose set of common solutions is denoted by $\Omega:=\cap_{i=1}^{\infty} \Omega_{i}$, where $\Omega_{i}$ denotes the set of solutions to generalized mixed equilibrium problem for $\theta_{i}, B_{i}$, and $\psi_{i}$.

Define a countable family of mappings $\left\{T_{r, i}\right\}_{i=1}^{\infty}: E \rightarrow C$ with $r>0$ as follows:

$$
\begin{array}{r}
T_{r, i}(x)=\left\{z \in C: \tau_{i}(z, y)+\frac{1}{r}\langle y-z, J z-J x\rangle \geq 0, \quad \forall y \in C\right\}, \\
\forall i \geq 1,
\end{array}
$$

where $\tau_{i}(x, y)=\theta_{i}(x, y)+\left\langle y-x, B_{i} x\right\rangle+\psi_{i}(y)-\psi_{i}(x)$, for all $x, y \in C, i \geq 1$. It has been shown by Zhang [15] that

(1) $\left\{T_{r, i}\right\}_{i=1}^{\infty}$ is a sequence of single-valued mappings;

(2) $\left\{T_{r, i}\right\}_{i=1}^{\infty}$ is a sequence of closed quasi- $\phi$-nonexpansive mappings;

(3) $\bigcap_{i=1}^{\infty} F\left(T_{r, i}\right)=\Omega$.

Now, we have the following result.

Theorem 9. Let $E$ be the same as that in Theorem 8, and let $C$ be a nonempty closed convex subset of E. Let $\left\{T_{r, i}\right\}_{i=1}^{\infty}$ : $C \rightarrow C$ be a sequence of mappings defined by (42) with $F:=\bigcap_{i=1}^{\infty} F\left(T_{r, i}\right) \neq \emptyset$. Let $\left\{\alpha_{n}\right\}$ be a sequence in $[0, \epsilon]$ for some $\epsilon \in(0,1)$, and let $\left\{\beta_{n}\right\}$ be a sequence in $[0,1]$ satisfying $0<$ $\liminf _{n \rightarrow \infty} \beta_{n}\left(1-\beta_{n}\right)$. Let $\left\{x_{n}\right\}$ be the sequence generated by

$$
\begin{aligned}
& x_{1} \in C ; \quad C_{1}=C, \\
& y_{n}=J^{-1}\left[\alpha_{n} J x_{n}+\left(1-\alpha_{n}\right) J z_{n}\right], \\
& z_{n}=J^{-1}\left[\beta_{n} J x_{n}+\left(1-\beta_{n}\right) J T_{r, i_{n}} x_{n}\right], \\
& C_{n+1}=\left\{v \in C_{n}: \phi\left(v, y_{n}\right) \leq \phi\left(v, x_{n}\right)\right\}, \\
& x_{n+1}=\prod_{C_{n+1}} x_{1}, \quad \forall n \geq 1,
\end{aligned}
$$

where $i_{n}$ satisfies the positive integer equation: $n=i+(m-$ $1) m / 2$, and $m \geq i(m \geq i, n=1,2, \ldots)$. Then, $\left\{x_{n}\right\}$ converges strongly to $\Pi_{F} x_{1}$ which is some solution to the system of generalized mixed equilibrium problems for $\left\{T_{r, i}\right\}_{i=1}^{\infty}$.

Proof. Note that $\left\{T_{r, i}\right\}_{i=1}^{\infty}$ are quasi- $\phi$-nonexpansive mappings; so, they are obviously generalized quasi- $\phi$-asymptotically nonexpansive. Therefore, this conclusion can be obtained immediately from Theorem 8 .

\section{Acknowledgments}

The author is greatly grateful to the referees for their useful suggestions by which the contents of this paper are improved. This work was supported by the National Natural Science Foundation of China (Grant no. 11061037).

\section{References}

[1] B. Ali and M. S. Minjibir, "Convergence of a hybrid iterative method for finite families of generalized quasi- $\phi$-asymptotically nonexpansive mappings," Fixed Point Theory and Applications, vol. 2012, article 121, 2012. 
[2] K. Goebel and W. A. Kirk, "A fixed point theorem for asymptotically nonexpansive mappings," Proceedings of the American Mathematical Society, vol. 35, pp. 171-174, 1972.

[3] S.-y. Matsushita and W. Takahashi, "A strong convergence theorem for relatively nonexpansive mappings in a Banach space," Journal of Approximation Theory, vol. 134, no. 2, pp. 257266, 2005.

[4] S. Plubtieng and K. Ungchittrakool, "Hybrid iterative methods for convex feasibility problems and fixed point problems of relatively nonexpansive mappings in Banach spaces," Fixed Point Theory and Applications, vol. 2008, Article ID 583082, 19 pages, 2008.

[5] S. S. Chang, H. W. Joseph Lee, and C. K. Chan, "A block hybrid method for solving generalized equilibrium problems and convex feasibility problem," Advances in Computational Mathematics. In press.

[6] L.-C. Ceng, S.-M. Guu, H.-Y. Hu, and J.-C. Yao, "Hybrid shrinking projection method for a generalized equilibrium problem, a maximal monotone operator and a countable family of relatively nonexpansive mappings," Computers \& Mathematics with Applications, vol. 61, no. 9, pp. 2468-2479, 2011.

[7] Y. F. Su, H. K. Xu, and X. Zhang, "Strong convergence theorems for two countable families of weak relatively nonexpansive mappings and applications," Nonlinear Analysis. Theory, Methods \& Applications, vol. 73, no. 12, pp. 3890-3906, 2010.

[8] E. U. Ofoedu and D. M. Malonza, "Hybrid approximation of solutions of nonlinear operator equations and application to equation of Hammerstein-type," Applied Mathematics and Computation, vol. 217, no. 13, pp. 6019-6030, 2011.

[9] Z. Wang, Y. Su, D. Wang, and Y. Dong, "A modified Halperntype iteration algorithm for a family of hemi-relatively nonexpansive mappings and systems of equilibrium problems in Banach spaces," Journal of Computational and Applied Mathematics, vol. 235, no. 8, pp. 2364-2371, 2011.

[10] S.-s. Chang, C. K. Chan, and H. W. J. Lee, "Modified block iterative algorithm for quasi- $\phi$-asymptotically nonexpansive mappings and equilibrium problem in Banach spaces," Applied Mathematics and Computation, vol. 217, no. 18, pp. 7520-7530, 2011.

[11] Y. Yao, Y.-C. Liou, and S. M. Kang, "Strong convergence of an iterative algorithm on an infinite countable family of nonexpansive mappings," Applied Mathematics and Computation, vol. 208, no. 1, pp. 211-218, 2009.

[12] H. Zegeye, E. U. Ofoedu, and N. Shahzad, "Convergence theorems for equilibrium problem, variational inequality problem and countably infinite relatively quasi-nonexpansive mappings," Applied Mathematics and Computation, vol. 216, no. 12, pp. 3439-3449, 2010.

[13] W. Nilsrakoo and S. Saejung, "Strong convergence theorems by Halpern-Mann iterations for relatively nonexpansive mappings in Banach spaces," Applied Mathematics and Computation, vol. 217, no. 14, pp. 6577-6586, 2011.

[14] S. S. Chang, H. W. J. Lee, C. K. Chan, and J. ai Liu, "Strong convergence theorems for countable families of asymptotically relatively nonexpansive mappings with applications," Applied Mathematics and Computation, vol. 218, no. 7, pp. 3187-3198, 2011.

[15] S.-S. Zhang, "Generalized mixed equilibrium problem in Banach spaces," Applied Mathematics and Mechanics, vol. 30, no. 9, pp. 1105-1112, 2009.

[16] S. S. Chang, J. K. Kim, and X. R. Wang, "Modified block iterative algorithm for solving convex feasibility problems in
Banach spaces," Journal of Inequalities and Applications, vol. 2010, Article ID 869684, 14 pages, 2010.

[17] Y. I. Alber, "Metric and generalized projection operators in Banach spaces: properties and applications," in Theory and Applications of Nonlinear Operators of Accretive and Monotone Type, vol. 178 of Lecture Notes in Pure and Applied Mathematics, pp. 15-50, Dekker, New York, NY, USA, 1996.

[18] I. Cioranescu, Geometry of Banach Spaces, Duality Mappings and Nonlinear Problems, vol. 62 of Mathematics and its Applications, Kluwer Academic Publishers Group, Dordrecht, The Netherlands, 1990.

[19] S. S. Chang, H. W. J. Lee, C. K. Chan, and W. B. Zhang, "A modified halpern-type iteration algorithm for totally quasi$\phi$-asymptotically nonexpansive mappings with applications," Applied Mathematics and Computation, vol. 218, no. 11, pp. 6489-6497, 2012.

[20] H. K. Xu, "Inequalities in Banach spaces with applications," Nonlinear Analysis. Theory, Methods \& Applications, vol. 16, no. 12, pp. 1127-1138, 1991. 


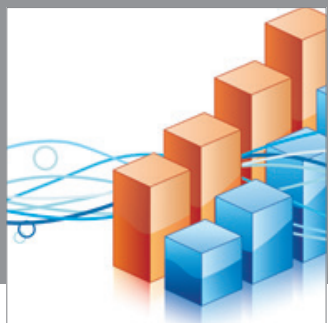

Advances in

Operations Research

mansans

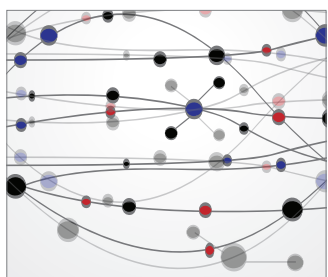

The Scientific World Journal
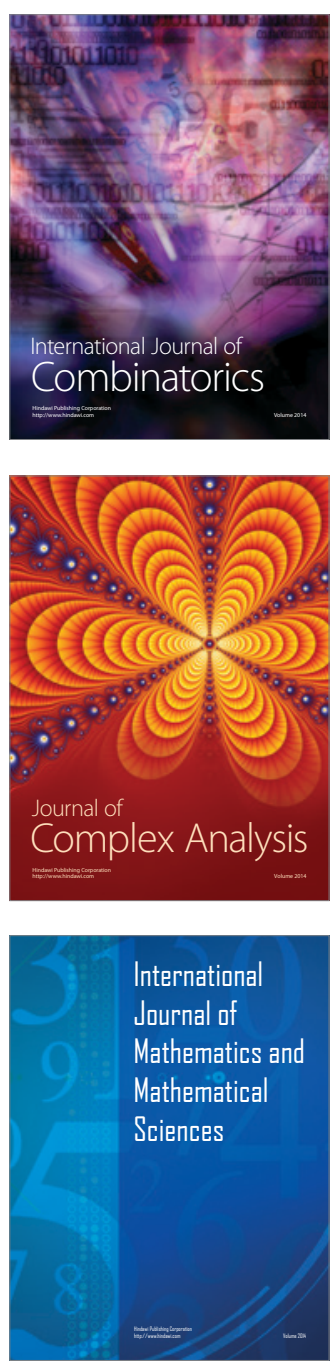
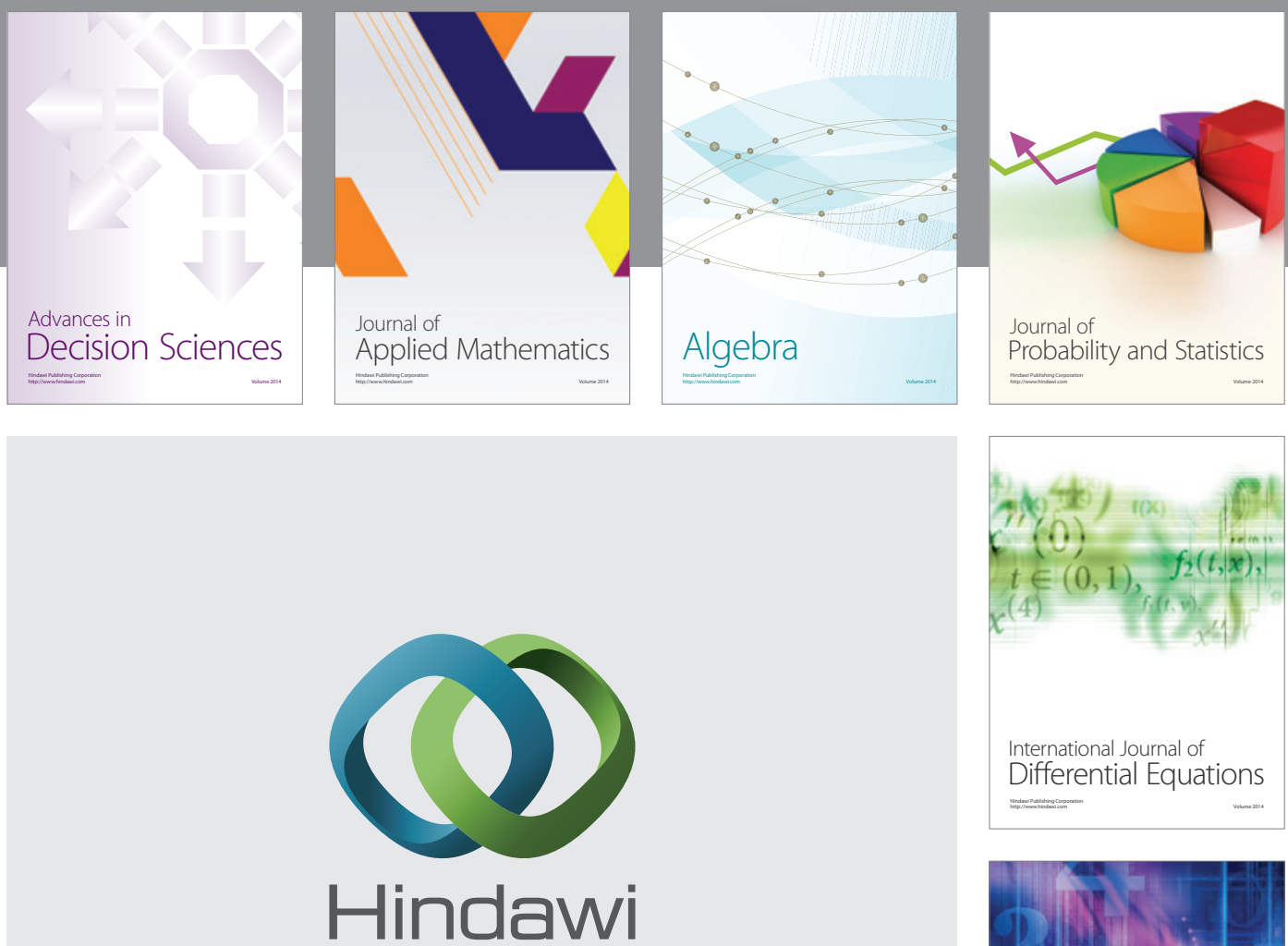

Submit your manuscripts at http://www.hindawi.com
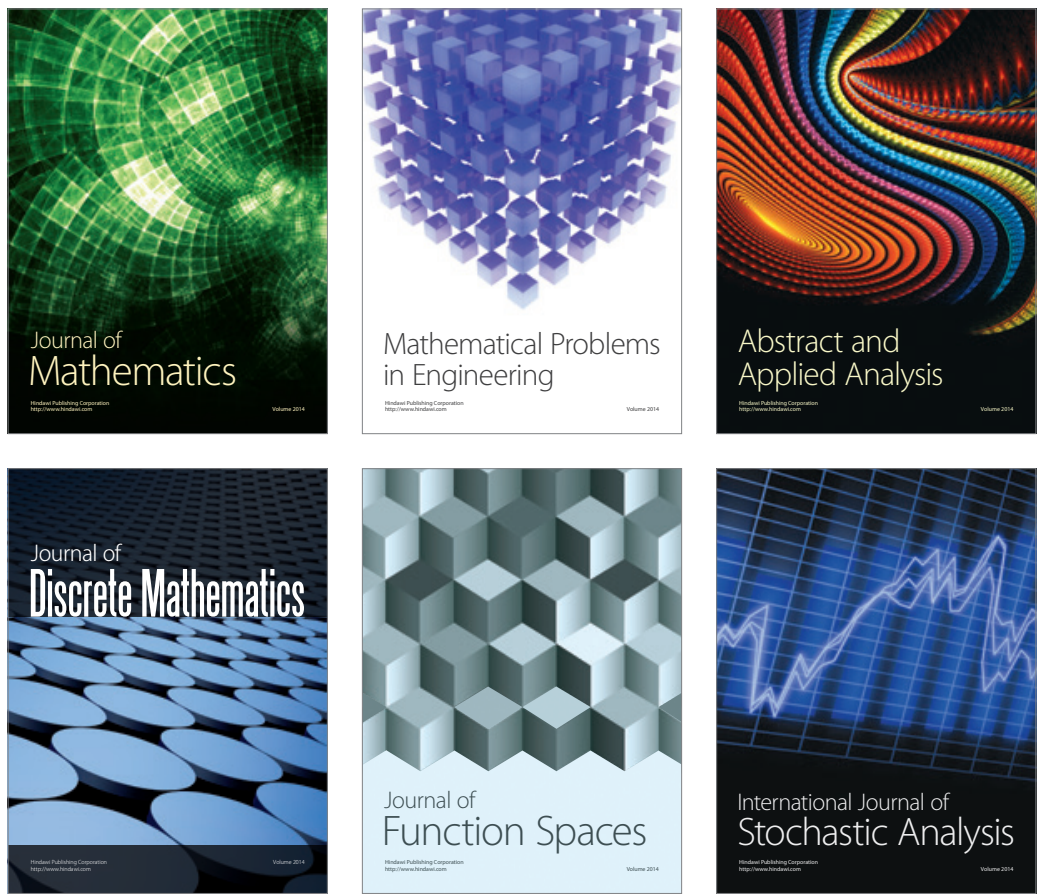

Journal of

Function Spaces

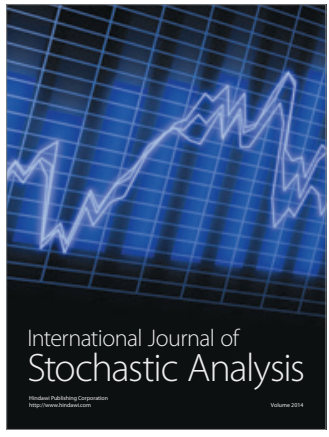

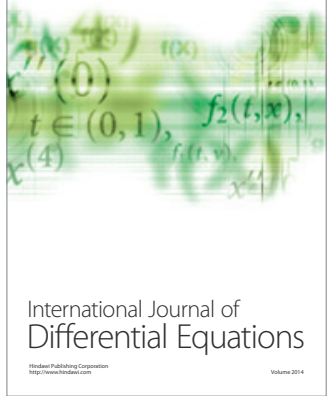
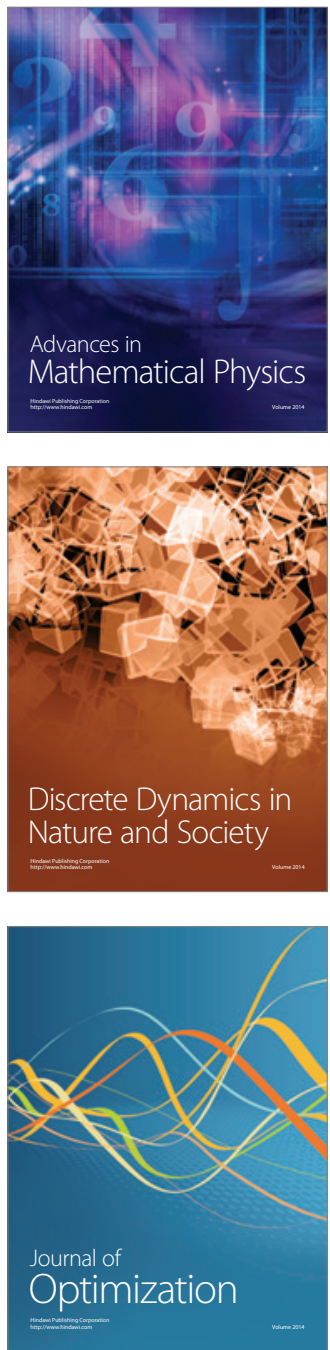